\title{
Role of health professionals in patient education
}

\author{
Jan A Maycock
}

Patient education is topical in the 1990 s, with some medical specialties having had longer experience of education than the specialty of rheumatology. Education of diabetic patients is perhaps the best example. The way in which members of a multidisciplinary team are prepared in the skills of teaching patients should perhaps be questioned. Little has been published on the skills required for education of patients in the United Kingdom, and what little there is seems to confuse the skill of teaching with the art of counselling.

The training curriculum for medical students, student nurses, and student physiotherapists makes little reference to this subject, though the new format of nurse training-Project $2000^{1}$ places a heavy emphasis on health education. Other encouraging moves have been made in rheumatology with post basic courses in rheumatology nursing, which have for a number of years included patient education skills. A new validated course for post basic physiotherapists in rheumatology, organised by the Association of Chartered Physiotherapists, Staffordshire, has also placed much stress on these skills.

Additionally, there is much evidence to indicate that many patients are dissatisfied with the amount and type of information given to them by health professionals. For example, the reports published by the health ombudsman ${ }^{2}$ criticise health professionals, particularly doctors and nurses, for their poor communication skills.

The specialty of rheumatology in the United Kingdom has derived its methods of educating patients primarily from the experience of other specialties and from the United States.

Care must be taken in setting up systems for patient education to ensure that the professionals appointed to these positions have the correct training and skills. Unfortunately, it has often been the case recently that nurse specialist posts are graded at staff nurse level. This means that the applicants are immature and do not have sufficient experience. The new clinical career structure for nurses should mean this poor practice of 'cheap labour' will be eradicated.

Community Health Services,

11 Orford Road, Walthamstow, London E17 9LP J A Maycock, senior nurse manager district nursing/quality assurance and consultant in rheumatology nursing difficulties: (a) leadership of the team; $(b)$ the nature of the corporate responsibility of the team and its effect on the responsibility of individual members; $(c)$ confidentiality and communications; (d) legal aspects of these matters.

The report also suggested that 'the difficulties seen in a multidisciplinary approach are more attributable to interpersonal jealousies than to anything more solid'. These jealousies may arise from such issues as the challenge to the traditional supremacy of doctors, the increasing assertiveness of nurses, the development of new psychological treatments, and the creation of new professional roles, such as the nurse practitioner.

An understanding of the role of all members of the team is obviously a fundamental requisite in establishing patient education strategies, to enable members of the team to trust the professional expertise of the other members. Brunner and Huffington ${ }^{4}$ used experiential techniques to show that occupational therapists, for example, felt that they were a group that was misunderstood and abused by other team members, who merely used them '. . . to keep patients quiet by weaving baskets'. It is easy to find many more examples of inappropriate referral within a team from one professional to another-perhaps the most common is the inappropriate referral for physiotherapy. Such referral is a waste of already overstretched resources and, additionally, sends patients a double message, completely negating the efficacy of the education programme, and perhaps giving unrealistic expectations of the possible results of treatment.

Coordination of patient education strategies

Shared care of patients with rheumatic disease is often current practice. This obviously offers a more complete and comprehensive approach to care but may mean that diverse information is given to them. Careful planning is needed in establishing education programmes as all too often these programmes are seen just as the domain of hospital therapists. This is unrealistic as the major proportion of patients' time is spent in the community where they seek advice from a whole plethora of different health personnel. For example, one patient may require treatment in the hospital outpatient department by a- rheumatologist, physiotherapist, nurse specialist, occupational therapist, and dietician. In the community the patient may also be treated by a general practitioner, practice nurse, district nurse, chiropodist, and pharmacist. The list is exhaustive with the poor patient as the central pivot around which all these professionals give a slightly different slant to the problem in hand.

HOH


Key roles in patient education

Coordination of the multidisciplinary team, especially in hospital, has traditionally been the domain of doctors. Consideration of the problems which hinder and fragment the team approach to patient education suggests that it may be preferable to choose another health professional to sort out problems and provide a link between the community and hospital. Before considering the way in which such a health professional can assist the learning process for patients the history of nurse specialists requires some comment.

The concept of an expanding role for nurses, which is embodied in the title 'specialist nurse', is not new. Certainly, Florence Nightingale and Bedford-Fenwick in the United Kingdom, and Lilian Wall in the United States reflected a scope of practice akin to that of today's 'new' practitioners. Florence Nightingale ${ }^{5}$ felt that a knowledge of nursing should concern itself with 'how to put the constitution in such a state as that it will have no disease, or that it can recover from disease', and viewed this as different from medicine. She placed great emphasis on clinical practice as the means of learning the art of nursing and stated, ' . . nothing but observation and experience will teach us the ways to maintain or to bring back the state of health ... Although observation and experience did become a vital part of nursing, it was used to assist the doctors and to meet the needs of the institution rather than to develop the science of nursing.

\section{Influence of specialisation on the nursing profession}

The first nurse specialists were clinical nurse specialists in psychiatry, in the United States, as early as 1958. Also, in the United States in the early 1960s nurse practitioners emerged, whose controversial role was to fill the gap in health care in poor rural areas where doctors could not be recruited to work.

Nursing specialisation is slowly coming of age in the United Kingdom, and has been acclaimed by a plethora of reports and reviews; perhaps the best known of these are the Briggs report, ${ }^{6}$ the neighbourhood nursing review, 7 Project $2000,{ }^{1}$ and, more recently, A Strategy For Nursing. ${ }^{8}$ It is therefore not surprising if nurses, health professionals, and the public are confused by the varied titles for specialist nurses, many of which tell little about the job. Thus, for example, the United Kingdom Central Council for Nursing perceives the specialist practitioner as follows: '.. We envisage a range of specialist practitioner roles in the hospital and the community. Some of these will be disease linked, others will represent specialist knowledge in nursing interventions or in health promotion. . . A number of specialist practitioners will develop additional skills and become team leaders who will work with a group of registered practitioners in a particular area of practice. They will act as resource persons for, and managers of, their groups'.

The Department of Health nursing division career development project group in its report to the NHS management board recently, recommended that a role entitled 'senior clinical practitioner' should be analysed and developed. This provides another conceptual framework around the role and a further variation on the title for the public.

Care must also be taken when eliciting the meaning of the neighbourhood nursing review, ${ }^{7}$ which mentions the nurse practitioner movement in America. Bullough has indicated that some American nurses practise as substitute doctors, diagnosing and treating patients, whereas others expand and advance the role of nursing rather than adopting a medical model. ${ }^{9}$

The perplexities of the specialist role nationally are reflected in the job vacancy columns, where all to often it seems that the 'left overs' are brought together under the fancy title, 'specialist nurse'. There is a need, therefore, to define clearly the term 'nurse specialist'. Perhaps the way forward is to define the role of clinical nurse specialist and nurse practitioner separately.

In the United Kingdom the role of clinical nurse specialists has been developed in many instances medically or with emphasis on a particular disease. Nurses, through advanced study and training, acquire knowledge above that expected of general nurses, which enables them to consider various alternatives when explaining the condition of a patient, predicting the future course of events, and prescribing nursing actions. In this country the work of clinical nurse specialists in diabetes nursing, psychiatry, and stoma care is perhaps the best known.

The rheumatology nurse practitioner role in the United Kingdom is complex and confusing as all too often this title is given to posts derived from a medical need and therefore focuses on signs, symptoms, pathology, prognosis, and the course of diseases. This disease oriented approach attends to the structure and functions of the body rather than to the total patient.

This role has been most effective when it has developed out of patients' needs. Thus, for example, Stillwell showed that the therapeutic value of the service of the nurse practitioner in general practice was different from but complementary to that of the general practitioner. ${ }^{10}$ Burke-Masters describes another such example ${ }^{11}$ among homeless and destitute men denied access to proper primary care by general practitioners. The need of these patients was the impetus for the development of her role as a nurse practitioner within the primary medical care project in the East End of London.

It is important to remember that only nurses who hold the responsibility for a complete caseload of patients are nurse practitioners in the truest sense of the word. One or two posts exist in rheumatology but, generally, they are rare. The use of such nurses in rheumatology is growing nationally, however, and interestingly, many of these posts originated owing to patient need $^{12}$-demands for information on the rheumatic diseases were increasingly made of already overstretched rheumatologists by patients attending outpatients. Only a small number of nurse practitioners in rheumatology provide a link between hospital and community 
and coordinate an effective: extended team approach to patient education, however.

\begin{abstract}
Metrologists
Metrologists should also play a significant part in patient education as they not only have the opportunity to discuss with patients the nature of proposed treatments but can also demonstrate the efficacy of treatments with subjective clinical assessments. Metrologists enable patients to feel that they are fully involved with the course of treatment with some say in its effectiveness, thus returning some control to the patients. Lack of control is often considered a major problem by those with a chronic disease.

This role is an interesting one as it is often carried out by different health professionals, such as occupational therapists, physiotherapists, and nurses. There is a division of opinion as to which group provides a more subjective assessment. Some think that it is difficult for nurses to be subjective as they have too great an understanding of pharmacology and therapeutic response. The metrologist and the nurse practitioner should work extremely closely as they perhaps will be the health professionals who will carry out the most intensive part of individual education programmes in the hospital outpatient department, general practitioner's surgery, and in the patients' homes.
\end{abstract}

\section{Extended team}

As previously stated unless interprofessional jealousies are guarded against the process of patient education will be severely interrupted. The team should frequently reappraise its education philosophy to allow efficient overlap of expertise rather than conservative protection of role definition. The qualities and experience of individual professionals should be taken into account alongside the realistic time allowance each member can put into the programme.

This networking and interlocking between health professionals can save much confusion for patients. For example, the patient who is being helped to understand the nature and course of his osteoarthritis and the realistic treatment options can be prescribed a simple analgesic by his doctor, who gives a simple explanation of the differences between these and non-steroidal anti-inflammatory drugs. The patient then sees the nurse specialist, who reaffirms this information, describes the disease, assesses the patient's body weight, and asks the dietician to advise on a reducing diet. The nurse can then provide support to aid compliance. The nurse can teach the patient about the importance of keeping muscles toned and, if necessary, refer the patient to a physiotherapist, who will assess and determine the individual treatment programme and carry it out. The physiotherapist's treatment will centre very much on education, and the patient can then pass back to the care of the nurse for reinforcement of this treatment regimen.

Sadly, this example of good practice for patients with osteoarthritis is not always followed for reasons which are often complex and controversial. All too often a general practitioner or the media might have given this patient unrealistic expectations of his hospital consultation. The patient will perhaps arrive in the hospital outpatient department expecting the rheumatologist to have a super new wonder drug up his sleeve for the treatment of osteoarthritis or may think that a course of physiotherapy will arrest the disease and remove symptoms. Published reports often state that patients recall most easily information they consider to be important. Therefore it is vital to try to change or to modify patients' initial unrealistic expectations of outcome or treatment available. A treatment such as physiotherapy, for example, should not be used simply because it is difficult to send patients away without anything. Such a practice renders the education programme useless and causes other team members considerable management problems in the future.

\section{Patients' problem areas}

The team will have to assess each patient's individual educational needs holistically as many of the patient's sociological, ethnic, and environmental needs must be considered to enable a suitable plan of care to be drawn up.

The response to illness differs greatly between patients. Mechanic describes illness behaviour as the patient's perceptions, feelings, and actions, which show the meaning of his symptoms, disability, and the resulting consequence on his daily life. ${ }^{13}$ So it is clearly evident that before embarking on any form of educational regimen the responses of patients with rheumatic disease to their illness need identifying. The educational strategy can then be tailored to those areas that are actually causing anxiety to the patients rather than to the areas that health professionals identify as a priority. It is useful to consider the list of resources which Mechanic identifies as used by patients in adapting to stressful life demands-for example, a chronic disabling disease such as rheumatoid arthritis.

1 Economic It is important that with the recent complex changes in social benefits, coupled with the increasing social deprivation in inner cities of disabled and elderly people, that the services of a skilled social worker are used. Early intervention is needed when it is required to enable the team to design an education programme which fits the patient's lifestyle. The Arthritis and Rheumatism Council point out that as many as 20 million people consult their general practitioners with some form of arthritis ${ }^{14}$; it is safe to say that not all these will visit a rheumatologist. The rheumatology nurse practitioner can work closely with the general practitioner to coordinate this vital part of extended team interlinkage into the community. 2 Skills and abilities These should be identified by the patient in partnership with the team, using the particular skills of the occupational therapist. If the patient is working the team needs to encourage the patient to try to cope for as long as possible. Where there are work problems the occupational therapist, physiotherapist, and nurse practitioner can use these 
problems constructively to illustrate the education programme. Where there are difficult problems the occupational therapist can liaise with the disablement resettlement officer for advice about job retraining, again bringing back this information for use in the personalised education plan.

3 Psychological defences. 'Denial' is often a word alluded to by health professionals when describing a patient's response to a chronic disabling disease. The team should work extremely closely together where this is an issue as education will not be possible until an assessment has been made of how much these defences are part of the patient's personality and therefore difficult to change.

The patient will have difficulty in understanding not only his illness, drugs, and his treatment programme but must be helped to understand the psychological and social side effects of living with a chronic illness and helped to develop the resources for coping with them. A patient who is overwhelmed by the pyschosocial difficulties of living with chronic illness will probably absorb little of the information offered by the team.

4 Personal reaction The personal reaction between patient and health professional must not be forgotten as Zeitlin ${ }^{15}$ suggests when talking about rheumatoid arthritis: 'the nature of rheumatoid arthritis, with its frequently progressive course, forces patient and healer alike to face the task of chronic mourning. The pyschological toll on the staff can be tremendous'. Therefore it should be remembered that there is a need for a strong bond of mutual support and understanding between the members of these professional disciplines who educate such patients and the patients themselves.

5 Motivational impetus The patient with minimal illness behaviour is likely to have a strong motivation. Baker suggests 'that motivation is a difficult thing to induce when missing. ${ }^{16}$ Some patients with intractable absence of motivation will prove to be those who had never managed an adequate adjustment to life before the disability appeared, and for whom the disability provides an adequate and less threatening explanation of the failure to succeed'.

Thus it can be seen that assessment of a patient's motivation is central to the formation of a programme of education. It will also give the team a guide as to how much change they may be able to make in the patient's lifestyle when trying to cope with disability.

Areas of skill which help in the design of patient education programmes

LEARNING LEVELS

Team members must understand the types and levels of learning they will encounter in the patients they are treating. Learning theorists have distinguished three types of learning: (1) Cognitive learning, which alludes to the process of thinking, of gaining information, and working through it. (2) Affective learning, which incorporates attitudes, values, beliefs, and feel- ings which create idiosyncratic reactions. This kind of learning is closely tied up with a patient's motivational drive. (3) Psychomotor skill learning, which is a skill learnt by practice-for example, a controlled neuromuscular movement that the physiotherapist might teach.

Gagne ${ }^{17}$ proposes eight categories of learning, the simplest of which is the development of involuntary behaviour through classical conditioning. He suggests that a subject needs to progress through each category successfully before achieving the next level. In other words a patient at the start of education merely recognises and responds to stimuli and then proceeds to more complex forms of learning, such as verbal associations, differentiation of stimuli, concept forming, and problem solving.

\section{MOTIVATION}

Health professionals playing a part in patient education programmes need to understand the motivations of human behaviour. Many different theories of motivation have been proposed. A cognitive theory of motivation has been put forward by Weiner, ${ }^{18}$ who suggests that people are considered as active participants in creating their own motivation through the desire to learn or in the anticipation of learning.

Application of a theory such as that of Weiner to the education of a patient with rheumatic. disease means that health professionals need to ascertain that there is some degree of need to learn and that this need requires a response such as education to ease the tension. Anxiety is a response to this need and if excessive may be detrimental to learning.

Psychologists describe two types of motivation: (a) intrinsic motivation, which is responsible for behaviour patterns which continue without reinforcement or reward and $(b)$ extrinsic motivation, which persists for only short periods after reinforcement stops if motivation has not become intrinsic. Clearly, therefore, there is an urgent need to encourage patients with rheumatic disease to develop intrinsic motivation. Coutts and Hardy ${ }^{19}$ clarify the two types of motivation still further by suggesting: 'The distinction between the two types of motivation helps to explain the low rate of compliance with prescribed regimens. In hospital, reinforcement is provided by health care workers, the patient complies and rarely has the opportunity to create his own motivation by considering his health problem and its effects. With the withdrawal of reinforcement out of hospital, the desired behaviour is likely to stop unless the patient has internalised the motivation'. Motivation should therefore be assessed early on in the treatment of a patient.

\section{COMMUNICATION}

Communication skills are the key to good practice when educating patients as information, support, and advice are essential in helping patients adapt to new and more limited lifestyles and for many chronic illnesses communication is virtually the only form of treatment there is. $\mathrm{McGee}^{20}$ interviewed patients in their homes 
after discharge from hospital and found that less than $40 \%$ complained about such things as nursing care or food, but $65 \%$ were dissatisfied with communication. Some studies have emphasised the significance of the interaction between health professionals and patients, pointing out that character differences can inhibit successful transfer of information. A study by Davis $^{21}$ showed that low patient compliance was associated with the fact that doctors did not seek patients' participation, gave no feedback, or were formal in their communication with patients.

Many studies have shown that there is a strong positive correlation between satisfaction with visits to the doctor and treatment compliance. Maguire ${ }^{22}$ devised an interview training scheme which, though designed primarily for use by doctors, can also be interpreted for use by health professionals engaged in patient education. The principal points are: $(a)$ give information about diagnosis and cause; $(b)$ avoid medical jargon; $(c)$ explore the patient's expectations and if these cannot be met, explain why; (d) do not confine the interview to objective medical information.

Problems in communication between patients and health professionals are usually caused by the patient not understanding or remembering what was said. This may occur because the information given is outside their intellectual or knowledge levels or because they have misconceptions which interfere with their understanding.

Ley's ${ }^{23}$ work with general practitioner's, in which he taught them skills of improving patients' recall, is also of great use in patient education. His results showed that patients of instructed practitioners recalled a significantly greater amount than patients of practitioners who had not received the instruction. His suggestions were as follows: (a) use explicit categorisation; $(b)$ repeat information in different ways if possible; (c) make advice giving as specific, detailed, and accurate as possible as opposed to making general statements.

Perhaps one of the commonest faults of health professionals when communicating with patients is their failure to realise how information they have given is open to individual interpretation. Often this confusion takes place after a consultation when the patient tries to recall the verbal or written instruction. Moskowitz and $\mathrm{Haug}^{24}$ illustrate this well by citing some real experiences: (1) 'Take this drug four times a day'. Since this means taking it every six hours, must I wake up in the middle of the night? What if I forget? Should I take two when I remember? (2) 'Take frequent baths to help you relax'. Are they supposed to be hot, cold, or warm? Should I soak for a while? Is four times a day frequent? Does it matter when? Does he think I'm too tense, that it's all in my head? (3) 'Only use this pill if you can't stand the pain'. What does 'can't stand' mean? How long should I wait? Is it bad to take it? If I do, am I a weak person?

Many health professionals have had experience of this type of communication problem, which is often picked up some time after a clinic visit-for example, when the occupational therapist is treating the patient at a later date. This means that the patient has probably been worrying over the problem and not seeing the doctor for another few months has taken the first opportunity to ask another member of the team. Much time and anguish could be saved if the team worked out a common approach and gave the patient a point of contact if worriedfor example, the specialist nurse.

Effective communication from the team should be therapeutic in itself. Gazda ${ }^{25}$ suggests that communication is a three phase cycle: facilitation, transition, and action. Within the cycle perhaps the most important phase is the foundation of the therapeutic relationship-that is, the facilitation phase. The essential features of this are talking, and listening in an empathetic, warm, non-directive, and non-judgmental way. Anxiety is then reduced and the patient is helped to feel relaxed, ask questions, and release emotion.

The challenge of identifying communication barriers should be taken up by every member of the educating team. Increased skill and awareness by all members of the team is important. Ewles $e t a^{26}$ suggest a list of pointers to look out for: $(a)$ a social and cultural gap between educator and client; $(b)$ limited receptiveness of client; (c) negative attitude to the health educator; $(d)$ limited understanding and memory; $(e)$ insufficient emphasis on education by the health professional; $(f)$ contradictory messages; and $(g)$ overcoming language barriers.

Possibly, the quantity of information given to patients at any one time, should be added to this list. Often, health professionals are tempted to distil knowledge and experience that they have acquired over many years in a few minutes. Moskowitz expands this theory further by suggesting that 'Some things can be told, some demonstrated, some only experienced, some written out, some stated a single time, and some repeated with variations. This in itself may lead to further realisation that the teaching cannot be done all at once or by the same person'. This statement confirms the importance of an extended team in rheumatology, who can formulate a coordinated approach to patient education.

\section{CONTROL}

The word control should feature strongly when health professionals are developing their skills in patient education. Many patients experiencing the trauma of discovering that they have a rheumatic disease, with the implications of possible chronicity, disability, and pain, feel that they have lost or are losing control of their lives. It might be suggested that one of the main objectives in educating patients with rheumatic disease is to give them an understanding of the disease process, its management, and the way in which they can adapt their lives to the illness. Arluke $^{27}$ in a study of elderly people with arthritis came to the same conclusion and saw the concept of care as going some way towards providing patients with help in their struggle to regulate and keep control of their lives. 
The way forward

The need for multidisciplinary teams to develop and improve their patient education skills in the future is paramount in view of an aging population, coupled with the incidence of rheumatic disease in the general population.

Patient education is rightly heralded as therapeutic by the professionals taking part in such programmes. In the light of the changes in the NHS proposed by the government's white paper much work will have to be done nationally to show the efficacy of such programmes.

1 United Kingdom Central Council for Nursing. Project 2000 $A$ new preparation for practice. London: UKCC, 1986.

2 National Health Service. Health Service commissioner, 4th Report for session 1977-1978. London: HMSO, 1977.

3 National Health Service. Commission on the National Health Service Report. (Chairman, Sir Alex Merrison.) London: HMSO, 1979.

4 Brunner H, Huffington C. Altered images. Nursing Times. 1985; July: 24-7.

5 Nightingale F. Notes on nursing. Philadelphia: Lippincott, 1946.

6 Briggs A. The report of the committee on nursing. London: HMSO, 1970. ((Cmnd 5115.)

7 Department of Health and Social Security. Neighbourhood nursing: a focus for care. London: HMSO, 1986.

8 Department of Health Nursing Division. A strategy for nursing: a report of the steering committee. London: HMSO, 1989.

9 Bullough B. Influences on role expansion. Am $\mathcal{F}$ Nurs 1976; 76: $1476-81$.

10 Stillwell B, Greenfield S, Drury V W M, Hull F M. A nurse practitioner in general practice: working style and pattern of consultations. $\mathcal{F} R$ Coll Gen Pract 1987; 37: 154-7.
11 Burke-Masters B. The nurse practitioner surgery. Self Health Magazine 1988; March: 22-3.

12 Melville J. Trouble shooter in the clinic. New Society Magazine 1988; 13 May: 84.

13 Mechanic D. Illness behaviour, social adaptation and the management of illness. A comparison of educational and medical models. $\mathcal{F}$ Nerv Ment Dis 1977; 165: 79-87.

14 Wood P. Arthritis and rheumatism in the eighties. London: The Arthritis and Rheumatism Council, 1986.

15 Zeitlin D. Psychological issues in the management of rheumatoid arthritis. Psychosomatics 1977; 18: 7-14

16 Baker G H B. Psychological management. In: Woolf D, ed. Clinics in rheumatic diseases. Philadelphia: Saunders, 1981: 455-67.

17 Gagne' R M. Essentials of learning for instruction. Hinsdale, Illinois: Dryden Press, 1974.

18 Weiner B. Human motivation New York: Holt, Rinehart and Winston, 1980.

19 Coutts L C, Hardy L K. Teaching health. London: Churchill Livingstone, 1985: 57

20 McGhee A. The patient's attitude to nursing care. Edinburgh: Churchill Livingstone, 1961.

21 Davis F. Passage through crisis: polio victims and their families. Indianapolis: Bobbs-Merrill, 1963.

22 Maguire G P. Training medical students to obtain a history of the current problems. In: Bennet A E, ed. Communications in medicine. London: Oxford University Press (for the Nuffield Provincial Hospitals Trust), 1976.

23 Ley P. Towards better doctor-patient communications. Contributions from social and experimental psychology. In: Bennet A E, ed. Communications in medicine. London: Oxford University Press, (for the Nuffield Provincial Hospitals Trust), 1976

24 Moskowitz R W, Haug M R. Arthritis and the elderly. New

25 Gazda G M, Walters R P, Childers W C. Human relations development: a manual for health sciences. London: Allyn and Bacon, 1975.

26 Ewles L, Simnett I. Promoting health. New York: Wiley, 1985: 98-102.

27 Arluke A. Judging drugs: patients' conceptions of therapeutic efficacy in the treatment of arthritis. Human Organisation 1980; 39: 84-8. 